\title{
Deep C diving: mapping the low-abundance modifications of the DNA demethylation pathway
}

\author{
John P Thomson, Jennifer M Hunter and Richard R Meehan*
}

\begin{abstract}
Two new studies imply that the reprogramming of 5-methylcytosine via TET- and TDG-family enzymes is both widespread throughout the genome and functionally significant.
\end{abstract}

In the mammalian genome, the dinucleotide $\mathrm{CpG}$ acts as a unique signaling module that can regulate the local chromatin environment through the recruitment of specific chromatin modifying proteins [1]. Although it is thought to be context specific, the general enzymatic acquisition of methylation at CpG dinucleotides by DNA methlytransferase enzymes (DNMTs) over promoter regions tends to be associated with gene silencing events and heterochromatin formation. The maintenance of 5-methylcytosine $(5 \mathrm{mC})$ modification patterns has since been implicated in many important roles in normal cell function during mammalian development and disease progression [1]. Although it is widely understood how DNA can become enzymatically methylated, less is known regarding the active removal of $5 \mathrm{mC}$ at specific loci, aside from the potential for passive loss during cell division in the absence of DNMT activity. In 2009, a second form of DNA modification, that of 5-hydroxymethylcytosine $(5 \mathrm{hmC})$, was rediscovered, and enzymatic oxidation reactions (involving the ten-eleven translocation (TET) proteins) responsible for generating $5 \mathrm{hmC}$ from $5 \mathrm{mC}$ were identified [2]. Subsequent work has since identified the downstream, TET-dependent, oxidative derivatives of $5 \mathrm{hmC}$, those of 5-formylcytosine $(5 \mathrm{fC})$ and 5-carboxylcytosine $(5 \mathrm{caC})$ [2]. This has led to the proposal of an active DNA demethylation cycle relying on the initial oxidation of $5 \mathrm{mC}$ into $5 \mathrm{hmC}$, through the TET family of enzymes, before further oxidation to the $5 \mathrm{fC}$ and $5 \mathrm{caC}$ derivatives (Figure 1a). In contrast to the more abundant

*Correspondence: richard.meehan@igmm.ed.ac.uk

MRC Human Genetics Unit, Institute of Genetics and Molecular Medicine, University of Edinburgh, Crewe Road, Edinburgh EH4 2XU, UK
$5 \mathrm{hmC}$ modification, these lower-abundance downstream intermediates are proposed to be removed by base excision repair mechanisms that are highly reliant on the thymine DNA glycosylase (TDG) protein, ultimately resulting in the replacement of modified cytosine with non-modified cytosine.

\section{Mapping the patterns of $5 \mathrm{fC}$ and $5 \mathrm{caC}$ in mouse embryonic stem cells}

Genome-wide patterns of $5 \mathrm{mC}$ and now $5 \mathrm{hmC}$ are becoming well characterized in a host of cell and tissue types with ever increasing complexity, ultimately driven by a host of recent technological advances [3,4]. In contrast, there is a distinct lack of understanding regarding the distributions of the $5 \mathrm{fC}$ and $5 \mathrm{caC}$ modified sequences, largely due to a lack of accurate methods to detect these low-abundance modifications; mass spectroscopy indicates that $5 \mathrm{fC}$ is at $2 \%$ and $5 \mathrm{caC}$ at $0.5 \%$ of the levels of $5 \mathrm{hmC}$ in mouse embryonic stem cells (mESCs), which in turn is only $4 \%$ as abundant as $5 \mathrm{mC}$ [5]. Two recent studies report on novel techniques for mapping both $5 \mathrm{fC}$ and $5 \mathrm{caC}$ modifications, as well as addressing the functionality of TET/TDG $5 \mathrm{mC}$ oxidation events that occur throughout the genome [6,7]. Through the use of highly specific antibodies raised against both $5 \mathrm{fC}$ and $5 \mathrm{caC}$, researchers led by Yi Zhang at Harvard University are able to map the genome-wide distributions of both derivatives of $5 \mathrm{hmC}$ [6]. In an analogous set of experiments, Song and colleagues from the laboratory of Chuan $\mathrm{He}$ at the University of Chicago expand upon their already successful chemical capture techniques to enrich for $5 \mathrm{hmC}$-marked DNA [7]. In short, by first modifying all endogenous $5 \mathrm{hmC}$ by glucosylation, they can then specifically reduce $5 \mathrm{fC}$-marked cytosines to $5 \mathrm{hmC}$ through the addition of sodium borohydride $\left(\mathrm{NaBH}_{4}\right)$ and then glycosylate these sites with a modified glucose group (6-azide-glucose) to which a disulfide biotin linker is attached for subsequent enrichment. In addition, the group also adapt techniques to visualize the $5 \mathrm{fC}$ modification at single-base resolution (fCAB-seq), overcoming the issues of discrimination between the modified forms of cytosine that arise in traditional bisulfite-based mapping. By employing these novel techniques, both studies 


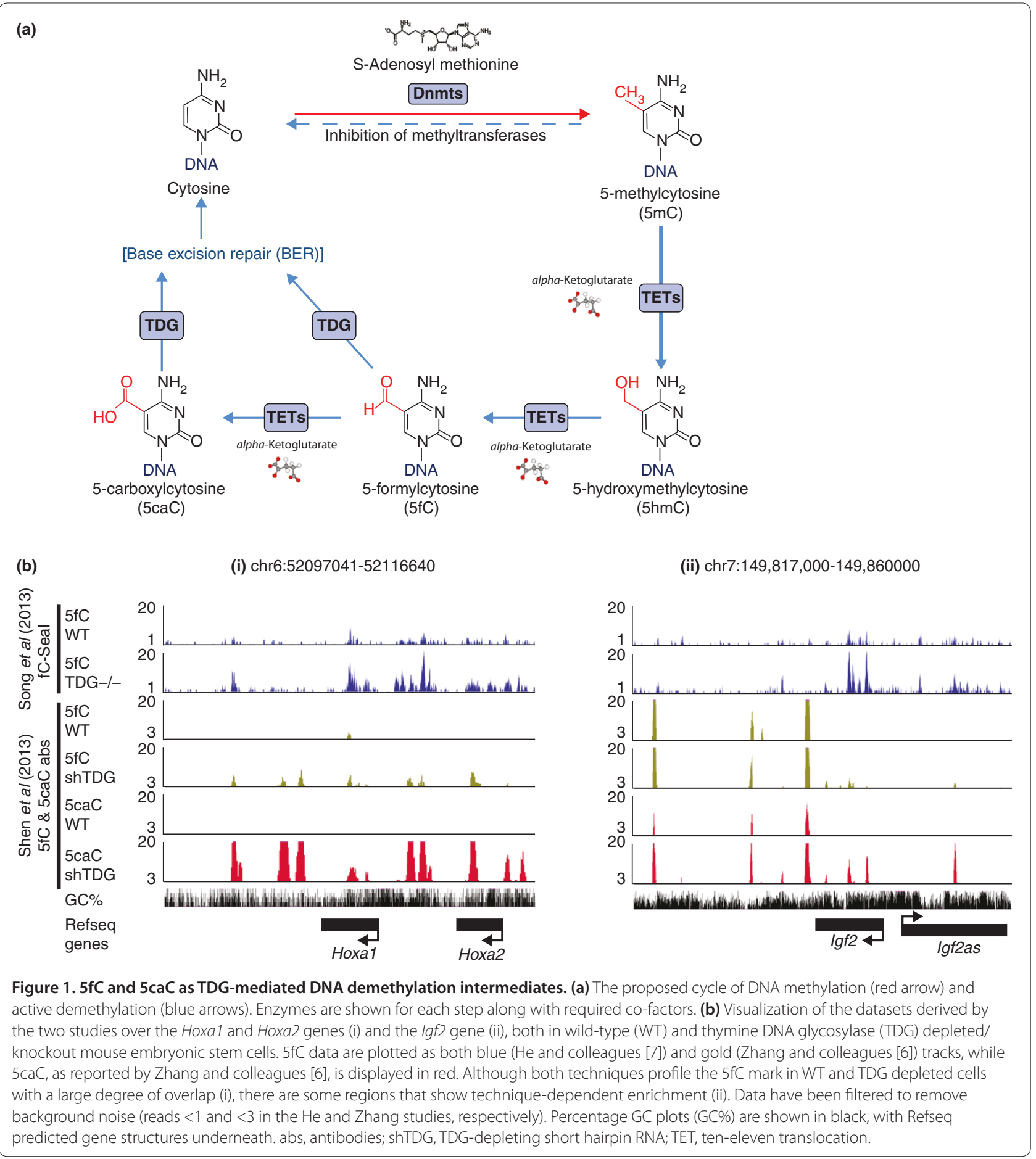

report the genome-wide patterns of $5 \mathrm{fC}$, in addition to $5 \mathrm{caC}$ in the Zhang study, in wild-type (WT) mESCs [6,7]. Typically sequence reads for both modifications are small in number in WT mESCs, consistent with a low abundance, but there is a suggestion of moderate levels of $5 \mathrm{fC}$ at repeat regions. The overall genomic distribution of $5 \mathrm{fC}$ and $5 \mathrm{caC}$ appears to be distinct from $5 \mathrm{hmC}$ in WT cells
[6], but this view should be interpreted with caution due to the relatively fewer number of reads for $5 \mathrm{fC}$ and $5 \mathrm{caC}$ compared with $5 \mathrm{hmC}$. Both studies recognized that enhancement of $5 \mathrm{fC}$ and $5 \mathrm{caC}$ levels in cells would improve data interpretation, so they derived similar biological strategies to improve the signal-to-noise ratio for their respective assay systems. 


\section{Visualizing sites of active demethylation by blocking base excision repair}

As the $5 \mathrm{fC}$ and $5 \mathrm{caC}$ derivatives are believed to be committed for rapid removal by base excision repairmediated mechanisms involving the protein TDG, the patterns of these two marks at steady state may not accurately reflect where demethylation is dynamically occurring in WT cells. To solve this problem the TDG protein was reduced to low levels either by short hairpin RNA interference [6] or through genetic manipulation in mESCs [7], to allow for the accumulation of both demethylation intermediates following TET-mediated oxidation of $5 \mathrm{mC}$ and $5 \mathrm{hmC}$ (Figure $1 \mathrm{~b}$ ). This increased the absolute levels of each modification and enhanced data quality and interpretation. Upon loss of TDG activity, many ectopic regions of $5 \mathrm{fC}$ and $5 \mathrm{caC}$ become apparent over genic and promoter-proximal regions; this contrasts with an earlier study that found $5 \mathrm{fC}$ enrichment in $\mathrm{CpG}$ islands (CGIs) of promoters and exons using a different assay technique [8]. The earlier study suggested CGI promoters, in which $5 \mathrm{fC}$ was relatively more enriched compared with $5 \mathrm{mC}$ or $5 \mathrm{hmC}$, corresponded to transcriptionally active genes. In the present studies, upon relating the TDG-mediated changes of $5 \mathrm{fC}$ and $5 \mathrm{caC}$ to the transcriptional activities of associated genes, both groups suggest that TDG-mediated $5 \mathrm{fC} / 5 \mathrm{caC}$ excision occurs preferentially at transcriptionally inactive promoters, implying a potential inhibitory role for the oxidative products at promoter proximal regions. No doubt these differing views will be amicably resolved in the future.

Many of the ectopic $5 \mathrm{fC}$ and $5 \mathrm{caC}$ peaks were found to correspond to regions bound by transcription factors such as Oct4 and Nanog, which themselves play key roles in the maintenance of pluripotency, as well as at sites of Polycomb-group protein binding. These results imply that TET/TDG-mediated $5 \mathrm{mC}$ oxidation may be a key event in the targeting of chromatin modifying proteins and transcription factors to specific loci. Interestingly, both of the studies report that upon TDG reduction/ removal, the majority of ectopic $5 \mathrm{fC}$ and $5 \mathrm{caC}$ is found at non-repetitive regions of the genome outside of promoters and exons, particularly over enhancer elements. After inhibition of TDG activity, the genomic distribution patterns of $5 \mathrm{caC}$ and $5 \mathrm{fC}$ are comparable with that of $5 \mathrm{hmC}$, which was not so obvious for the WT cells [6]. Closer analysis reveals a strong enrichment for both $5 \mathrm{fC}$ and $5 \mathrm{caC}$ at poised (H3K4me1 but not H3K27ac marked) enhancer elements, implying that $5 \mathrm{mC}$ oxidation may be crucial for the priming of such regulatory regions. Comparison to transcription factor binding site data indicated that TDG-dependent regulation of $5 \mathrm{fC}$ occurs preferentially at Tet1-, Tet2-, p300- and CTCF-binding regions in $\mathrm{mESCs}$ [7].

\section{Interpreting DNA demethylation}

As TET/TDG-mediated changes to cytosine modification states have now been shown to occur over a large number of genes and regulatory elements, this work reveals the potential for active DNA demethylation throughout the genome. Functionally, it is difficult to interpret how such modifications affect the overall epigenomic and transcriptomic landscape of the cells. The relationship between transcriptional state and DNA demethylation appears to be a complex affair. Upon depletion of TDG, only a small proportion of genes actually change in their expression state (99 genes with $P$-values $<0.01$ and a fold change $>1.5$-fold; or 1,192 genes with $P$-values $<0.01$ alone). In contrast, relative global changes in the levels of both $5 \mathrm{fC}$ and $5 \mathrm{caC}$ are extensive. Mass spectrometry analysis indicates that global levels of $5 \mathrm{fC}$ and $5 \mathrm{caC}$ increased by 5.6-fold and 8.4-fold, respectively, in response to TDG knockdown; $5 \mathrm{mC}$ and $5 \mathrm{hmC}$ levels were not altered [6]. Furthermore, ectopic peaks of $5 \mathrm{fC}$ and $5 \mathrm{caC}$ accumulate outside of promoters and enhancers, such as those at the 3 ' ends of genes, at sites that do not align to annotated regions of TDG binding [9]. As such, other proteins may be able to facilitate the base excision repair of the oxidative products of $5 \mathrm{mC} / 5 \mathrm{hmC}$ in the absence of TDG.

In view of the low levels of these marks, it is impressive how comparable many of the conclusions are between the two studies, particularly as antibody-based methods of enrichment on low-abundance proteins and DNA modifications are challenging when compared with chemical capture based techniques (Figure 1b). Although semiquantitative, the relative enrichments of the modifications (particularly in TDG-depleted/knock-out cell lines) suggest that the marks may either be snapshots of active demethylation at key regulatory regions or 'memories' of recent transcription events. The impression is of a poised environment that is permissive for rapid transcription upon the binding of relevant factors, a feature that would be highly relevant to pluripotent cells undergoing developmentally induced reprogramming changes in response to signaling cascades. It will be interesting to determine the genome-wide patterns of both $5 \mathrm{fC}$ and $5 \mathrm{caC}$ in somatic samples containing globally higher levels of $5 \mathrm{hmC}$ modifications [10]. However, the data suggest that it will be a challenge to detect these low-abundance modifications in WT cells without first blocking endogenous base excision repair, but perhaps there are more surprises to come.

\section{Abbreviations}

5caC, 5-carboxylcytosine; 5fC, 5-formylcytosine; $5 \mathrm{hmC}$,

5-hydroxymethylcytosine; 5mC, 5-methylcytosine; CGI, CpG island; DNMT,

DNA methlytransferase; fCAB-seq, formyl-chemically assisted bisulfite sequencing; mESC, mouse embryonic stem cell; TDG, thymine DNA

glycosylase; TET, ten-eleven translocation.

Competing interests

The authors declare that they have no competing interests. 


\section{Acknowledgements}

Thanks to Dr Colm Nestor (Linköping University Hospital, Sweden) for insightful comments. Many thanks to Keith Szulwach (School of Medicine, University of Chicago, IL, USA) and Hao Wu (Harvard University, Cambridge, MA, USA) for providing $5 \mathrm{fC}$ and $5 \mathrm{caC}$ datasets. JT is a recipient of IMI-MARCAR funded career development fellowships at the MRC HGU. RM and JH are supported by Medical Research Council. Work in RM's laboratory is supported by the MRC, IMI-MARCAR and the BBSRC.

\section{Published: 29 May 2013}

\section{References}

1. Reddington JP, Pennings $S$, Meehan RR: Non-canonical functions of the DNA methylome in gene regulation. Biochem J 2013, 451:13-23.

2. Koh KP, Rao A: DNA methylation and methylcytosine oxidation in cell fate decisions. Curr Opin Cell Biol 2013, 25:152-161.

3. Shen L, Zhang Y: 5-Hydroxymethylcytosine: generation, fate, and genomic distribution. Curr Opin Cell Biol 2013. doi: 10.1016/i.ceb.2013.02.017

4. Nestor CE, Ottaviano R, Reddington J, Sproul D, Reinhardt D, Dunican D, Katz E, Dixon JM, Harrison DJ, Meehan RR: Tissue type is a major modifier of the 5-hydroxymethylcytosine content of human genes. Genome Res 2012, 22:467-477.

5. Ito S, Shen L, Dai Q, Wu SC, Collins LB, Swenberg JA, He C, Zhang Y: Tet proteins can convert 5-methylcytosine to 5 -formylcytosine and 5-CArboxylcytosine. Science 2011, 333:1300-1303.
6. Shen L, Wu H, Diep D, Yamaguchi S, D'Alessio AC, Fung HL, Zhang K, Zhang Y: Genome-wide analysis reveals TET- and TDG-dependent 5-methylcytosine oxidation dynamics. Cell 2013, 153:692-706.

7. Song CX, Szulwach KE, Dai Q, Fu Y, Mao SQ, Lin L, Street C, Li Y, Poidevin M, Wu H, Gao J, Liu P, Li L, Xu GL, Jin P, He C: Genome-wide profiling of 5-formylcytosine reveals its roles in epigenetic priming. Cell 2013, 153:678-691.

8. Raiber EA, Beraldi D, Ficz G, Burgess HE, Branco MR, Murat P, Oxley D, Booth MJ, ReikW, Balasubramanian S: Genome-wide distribution of 5 -formylcytosine in embryonic stem cells is associated with transcription and depends on thymine DNA glycosylase. Genome Bio/ 2012, 13:R69.

9. Dalton SR, Bellacosa A: DNA demethylation by TDG. Epigenomics 2012, 4:459-467.

10. Thomson JP, Hunter JM, Lempiainen H, Muller A, Terranova R, Moggs JG, Meehan RR: Dynamic changes in 5-hydroxymethylation signatures underpin early and late events in drug exposed liver. Nucleic Acids Res 2013. doi: 10.1093/nar/gkt232

doi:10.1186/gb-2013-14-5-118

Cite this article as: Thomson JP, et al:: Deep C diving: mapping the lowabundance modifications of the DNA demethylation pathway. Genome Biology 2013, 14:118. 